Published in final edited form as:

ACS Infect Dis. 2018 June 08; 4(6): 1030-1040. doi:10.1021/acsinfecdis.8b00074.

\title{
Potent 1,2,4-Triazino[5,6b]indole-3-thioether Inhibitors of the Kanamycin Resistance Enzyme Eis from Mycobacterium tuberculosis
}

\author{
Huy X. Ngo ${ }^{\dagger}$, , Keith D. Green ${ }^{\dagger, \uparrow, ~ C h a t h u r a d a ~ S . ~ G a j a d e e r a ~}{ }^{\dagger}$, Melisa J. Willby ${ }^{\ddagger}$, Selina Y. L. \\ Holbrook $^{\dagger}$, Caixia Hou ${ }^{\dagger}$, Atefeh Garzan ${ }^{\dagger}$, Abdelrahman S. Mayhoub§, ${ }^{\prime}$, James E. Posey ${ }^{\ddagger}$, \\ Oleg. V. Tsodikov ${ }^{\star}, \dagger$, and Sylvie Garneau-Tsodikova ${ }^{\star}, \dagger, \S$ \\ †Department of Pharmaceutical Sciences, University of Kentucky, Lee T. Todd, Jr. Building, 789 \\ South Limestone Street, Lexington, Kentucky 40536-0596, United States \\ ‡Division of Tuberculosis Elimination, National Center for HIV/AIDS, Viral Hepatitis, STD, and TB \\ Prevention, Centers for Disease Control and Prevention, 1600 Clifton Road, Atlanta, Georgia \\ 30329, United States
}

§Department of Medicinal Chemistry and Life Sciences Institute, University of Michigan, 210 Washtenaw Avenue, Ann Arbor, Michigan 48109, United States

\begin{abstract}
A common cause of resistance to kanamycin (KAN) in tuberculosis is overexpression of the enhanced intracellular survival (Eis) protein. Eis is an acetyltransferase that multiacetylates KAN and other aminoglycosides, rendering them unable to bind the bacterial ribosome. By highthroughput screening, a series of substituted 1,2,4-triazino [5,6b]indole-3-thioether molecules were identified as effective Eis inhibitors. Herein, we purchased 17 and synthesized 22 new compounds, evaluated their potency, and characterized their steady-state kinetics. Four inhibitors were found not only to inhibit Eis in vitro, but also to act as adjuvants of KAN and partially restore KAN sensitivity in a Mycobacterium tuberculosis KAN-resistant strain in which Eis is upregulated. A crystal structure of Eis in complex with a potent inhibitor and CoA shows that the inhibitors bind in the aminoglycoside binding site snugly inserted into a hydrophobic cavity. These
\end{abstract}

\footnotetext{
*Corresponding Authors: sylviegtsodikova@uky.edu. Phone: 859-218-1686. oleg.tsodikov@uky.edu. Phone: 859-218-1687.

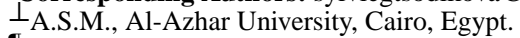

IlThese authors contributed equally to this work.

Supporting Information

The Supporting Information is available free of charge on the ACS Publications website at DOI: 10.1021/acsinfecdis.8b00074 . Details of all experimental procedures for synthesis and characterization of all compounds and intermediates, Eis chemical library screening, hit validation, inhibition kinetics, mode of inhibition, selectivity of inhibitors toward Eis, Mtb MIC value determination, dose-dependent $M t b$ MIC values determination, mammalian cytotoxicity measurements, and crystallization/diffraction/structure determination for EisC204A-CoA-inhibitor 39b complex; all ${ }^{1} \mathrm{H}$ and ${ }^{13} \mathrm{C}$ NMR spectra and HPLC traces for molecules generated; $\mathrm{IC}_{50}$ curves corresponding to data presented in Table 1; bar graph displaying the mammalian cell cytotoxicity of KAN; table of full list of compounds tested and their respective activity; table of X-ray diffraction data collection and refinement statistics (PDF)

Accession Codes

EisC204A-CoA-inhibitor 39b structure was deposited in the Protein Data Bank (PDB) with accession number 6B3T. Authors will release the atomic coordinates and experimental data upon article publication.

The authors declare no competing financial interest.
} 
inhibitors will undergo preclinical development as novel KAN adjuvant therapies to treat KANresistant tuberculosis.

\section{Graphical Abstract}

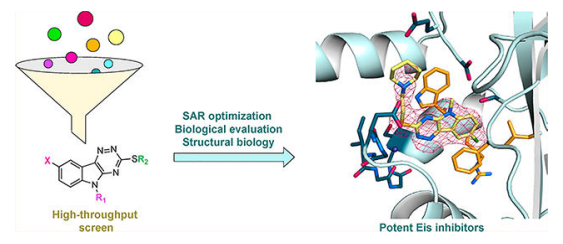

\section{Keywords}

aminoglycoside resistance; antitubercular agent; combination therapy; high-throughput screen; structure-activity relationship (SAR)

Mycobacterium tuberculosis (Mtb), the etiological agent of tuberculosis (TB), is a dominant worldwide threat to human health. ${ }^{1,2}$ The evolution of resistance of this bacterium to conventional antitubercular drugs has exacerbated the problem. ${ }^{3,4}$ This is particularly concerning as in the last 50 years only two new antitubercular agents, bedaquiline (Food and Drug Administration (FDA), USA) and delamanid (European Medicines Agency, EU), were approved by these agencies for treatment of multidrug-resistant tuberculosis (MDR-TB) and extensively drug-resistant tuberculosis (XDR-TB), respectively. ${ }^{5}$ The need to combat drugresistant TB remains a pressing issue, and work toward developing new antitubercular agents continues to be at the forefront of TB research. Several directions are being pursued in TB drug development: (i) investigation of chemical modifications of current TB treatments (e.g., isoniazid and rifampin), (ii) development of agents inhibiting already exploited targets, but capable of avoiding the resistance mechanisms (e.g., KatG and topoisomerase mutations), (iii) development of inhibitors of novel pathways or enzymes that are specific to Mtb or bacteria in general (e.g., mycolic acid pathway, amino acid biosynthesis, PanK, and dihydrofolate reductase), and (iv) development of inhibitors of resistance enzymes (e.g., $\mathrm{BlaC}$ and Eis) as adjuvants of currently approved antitubercular drugs. ${ }^{6,7}$

Aminoglycosides (AGs) have been used extensively to treat a broad spectrum of bacterial infections since the discovery of streptomycin in the 1950s. The injectable AGs, kanamycin (KAN) and amikacin (AMK), have been effcacious therapeutic agents against $M t b$ strains for decades. However, KAN- and AMK-resistant $M t b$ strains have emerged. $M t b$ has three main mechanisms to overcome the action of KAN and AMK: (i) increased expression of the enhanced intracellular survival (eis) gene as a result of a mutation in its promoter, ${ }^{8}$ (ii) increased expression of Eis and the effux pump, Tap, due to upregulation of transcriptional activator WhiB $7,{ }^{9}$ and (iii) ribosome mutations that interfere with AG binding. ${ }^{10}$ Upregulation of the eis gene by either mechanism (i) or (ii) confers resistance to KAN in one-third of KAN-resistant clinical isolates. ${ }^{8,9}$ Eis is a unique AG acetyltransferase (AAC) due to its distinct structure and ability to multiacetylate AGs at several different positions including the 3 "'-amine of 4,6-disubstituted 2-deoxystreptamine AGs and 4"'-amine of AGs containing an (S)-4-amino-2-hydroxybutyryl group that are not modified by other AACs. 
11,12 It is also of note that one AG modification may not completely abolish the antibacterial activity of an AG, whereas two or more modifications fully eliminate this activity. ${ }^{13}$ Eis has a larger and more complex active site than that of other AACs, which results in its broader substrate profile and multiacetylating activity. ${ }^{11,12,14}$ The kinetics of AG acetylation by Eis have been studied, and this bisubstrate enzyme was-found to operate by a random sequential mechanism. ${ }^{15}$

Two potential strategies that may be envisioned to overcome the resistance caused by Eis are (i) identification of new AGs that are not susceptible to inactivation by Eis, and (ii) discovery of structurally unrelated inhibitors of Eis, which would sensitize the KANresistant bacteria to KAN when administered as a combination therapy. Because Eis can acetylate multiple amines on clinically relevant AGs of different structures, the first strategy is not likely to be productive. We recently demonstrated that the second strategy is a useful approach by discovering several structural classes of potent Eis inhibitors and demonstrating that they indeed target Eis in Mtb cells. ${ }^{16-20}$ Diversifying a drug pipeline with different structural classes early on in the drug development process increases the chances of one of the compounds progressing to clinical applications. Development of drugs that need to act in the Mtb cytoplasm is especially complicated by the requirement for these molecules to cross the extremely waxy Mtb envelope as well as the membrane of the macrophage, which harbors persistent Mtb infections. Therefore, we sought a structural class of Eis inhibitors that would be distinct from those that we discovered previously.

In this study, we present novel 1,2,4-triazino[5,6b]indole-3-thioether-based Eis inhibitors. The structures of these inhibitors are unique as they contain a tricyclic core and a long flexible linker, which allows access to novel binding surfaces of Eis that were unexplored in our previous Eis inhibitor studies. We also introduce a simple and easily scalable synthetic route to derivatize the 1,2,4-triazino[5,6b]indole-3-thioether scaffold. We present kinetic and crystallographic analyses of these inhibitors as well as describe their biological activity as KAN adjuvants. We also perform a thorough comparison of the interactions of this scaffold with those of four previously published divergent Eis inhibitor classes.

\section{RESULTS AND DISCUSSION}

\section{Identification of Lead Compounds and Synthetic Optimization.}

Inhibitors of Eis were sought by a high-throughput screening (HTS) assay against a collection of $\sim 23000$ compounds from three different libraries: the BioFocus NCC library ( 1000 compounds), the ChemDiv library ( 20000 compounds), and the MicroSource MS2000 library ( 2000 compounds). ${ }^{16}$ The average $\mathrm{Z}^{\prime}$ score for the HTS was 0.65 , indicating assay robustness. Forty-six compounds with a 1,2,4-triazino[5,6b]indole-3thioether core substituted at three different positions were present in the HTS (Figures 1 and 2). Of these 46 compounds, seven molecules (14a, 23a, 23c, 37b, 37d, 39b, and 40b; Figure 2), some of which displayed Eis inhibition, were selected for additional investigation (Table 1). Four (14a, 37b, 37d, and 39b) of these seven molecules were confirmed to be Eis inhibitors by the dose-response assays. Seventeen additional compounds (Figure 2) were purchased to further explore the utility of this scaffold. On the basis of $\mathrm{IC}_{50}$ data obtained for the commercially available compounds against purified Eis (Table 1), 22 new derivatives 
(Figure 2) were synthesized. Two of the purchased molecules (37b and 39b) were resynthesized as controls to establish the validity of the data obtained from externally procured materials (Scheme 1). As neomycin B (NEO) was found to be one of the best substrates for Eis in a previous study, ${ }^{11,16}$ the HTS was performed with NEO as a substrate for optimal signal-to-noise ratio relative to the background hydrolysis of acetyl coenzyme A (AcCoA). However, as KAN is the clinically relevant substrate for inactivation by Eis in $M t b$, we determined $\mathrm{IC}_{50}$ of our synthesized compounds with KAN as a substrate $\left(\mathrm{IC}_{50, \mathrm{KAN}}\right)$.

The synthesis of all compounds started with the $N$-alkylation with alkyl halides of commercially available compounds $\mathbf{5 4}$ and $\mathbf{5 5}$ to afford in quantitative yields compounds $\mathbf{5 6}$ and 57, respectively. The resulting products were mixed with thiosemicarbazide in the presence of potassium carbonate or cesium carbonate, followed by acidification with concentrated hydrochloric acid to generate the 1,2,4-triazino[5,6- $b$ ] indole-3-thione or hydrazinecarbothiamide analogues $\mathbf{5 8 - 5 9}$ in $22-52 \%$ yields. Subsequently, intermediates 58-59 were reacted with various alkyl halides to obtain the desired S-substituted products (32 and 34-49) with a fluoro or a methyl group at the C8-position (indicated as X in Scheme 1) in $14-82 \%$ yields. The free hydroxyl group of $\mathbf{3 2} \mathbf{b}$ was methylated in the presence of iodomethane and sodium hydride to generate $\mathbf{3 3 b}$ in $47 \%$ yield. Compound $\mathbf{5 8 b}$ was reacted with bromoacetonitrile to afford the desired molecule $47 \mathrm{~b}$ in $63 \%$ yield. Compounds $\mathbf{5 2 - 5 3}$ were prepared in three steps from $\mathbf{5 8 b} . S$-Methylation of compound $\mathbf{5 8 b}$ with iodomethane afforded 60b (91\% yield), which was oxidized with $m$-CPBA to give sulfone $\mathbf{6 1 b}$ ( $45 \%$ yield). Compound $\mathbf{6 1 b}$ was reacted with different $N, N$-dialkylaminoalkylamines to generate the desired compounds $\mathbf{5 2}$ and $\mathbf{5 3}$.

\section{Structure-Activity Relationship (SAR) Study.}

Inhibitory activity $\left(\mathrm{IC}_{50}\right)$ against purified Eis (Tables 1 and $\mathrm{S} 1$ and Figures $\mathrm{S} 79-\mathrm{S} 85$ ) was determined for a total of 46 compounds. Examination of the activity of this series of derivatives of the 1,2,4-triazino[5,6b]indole-3-thioether scaffold (Tables 1 and S1, Figure 2) revealed several SAR insights. Our chemical library can be divided into four chemical series (I, II, III, and IV; Figure 2). Series I contains the 1,2,4-triazino[5,6b]indole-3-thioether core with a hydrogen atom at the C8-position, while series II and III contain a fluoro and a methyl substituent at this position, respectively. In series IV, a subgroup of series II, we replaced the thioether at the $\mathrm{C} 3$-position of the core by secondary amines in an effort to understand the biological importance of a sulfur atom at this position.

We first assessed the importance of the substituent at the C8-position (H "series I" vs F "series II" vs methyl "series III"). We compared the Eis inhibitory activity of compounds from series I, II, and III, with matching $\mathrm{R}_{1}$ and $\mathrm{R}_{2}$ groups when using $\mathrm{KAN}$ as the $\mathrm{AG}$ substrate $\left(\mathrm{IC}_{50, \mathrm{KAN}}\right)$. To understand whether the fluoro substitution was beneficial, we compared compounds from series I and II. We looked at compound $\mathbf{1 1 b}$ (series I, $\mathrm{X}=\mathrm{H}, \mathrm{R}_{1}$ $=$ methyl, and $\mathrm{R}_{2}=2$-(piperidin-1-yl)ethyl; $\mathrm{IC}_{50, \mathrm{KAN}}=0.23 \pm 0.02 \mu \mathrm{M}$ ) and its $\mathrm{C} 8$ fluorinated counterpart 39b from series II $\left(\mathrm{IC}_{50, \mathrm{KAN}}=0.030 \pm 0.005 \mu \mathrm{M}\right)$ and noticed that compound $39 \mathrm{~b}$ was much more potent. Similarly, we observed that compound 11c (series I, $\mathrm{X}=\mathrm{H}, \mathrm{R}_{1}=$ ethyl, and $\mathrm{R}_{2}=2$-(piperidin-1-yl)ethyl; $\mathrm{IC}_{50, \mathrm{KAN}}=0.27 \pm 0.05 \mu \mathrm{M}$ ) and its C8- 
fluorinated counterpart 39c from series II $\left(\mathrm{IC}_{50, \mathrm{KAN}}=0.14 \pm 0.01 \mu \mathrm{M}\right)$ displayed a similar trend, with the fluoro-substituted compound $39 \mathrm{c}$ being about twice as potent. These observations showed that adding a fluorine atom at the $\mathrm{C} 8$-position increased the potency of Eis inhibition. Next, we explored the effect of replacing the C8-hydrogen of series I or the C8-fluoro of series II by a methyl group (series III). Compounds 48d (series III, X = methyl, $\mathrm{R}_{1}=\mathrm{n}$-propyl, and $\mathrm{R}_{2}=2$ - $\left(N, N\right.$-diethylamino)ethyl; $\left.\mathrm{IC}_{50, \mathrm{KAN}}=0.15 \pm 0.02 \mu \mathrm{M}\right)$ and its $\mathrm{R}_{1}$ $=\mathrm{N} 5-i$-pentyl counterpart $48 \mathrm{~h}\left(\mathrm{IC}_{50, \mathrm{KAN}}=0.54 \pm 0.13 \mu \mathrm{M}\right)$, both with a methyl at their $\mathrm{C} 8-$ position, were slightly more potent than their direct respective counterparts with a fluorine at the C8-position, 37d $\left(\mathrm{IC}_{50, \mathrm{KAN}}=0.8 \pm 0.1 \mu \mathrm{M}\right)$ and 37h $\left(\mathrm{IC}_{50, \mathrm{KAN}}=1.3 \pm 0.1 \mu \mathrm{M}\right)$. On the other hand, in the case of compounds $37 \mathrm{~b}$ (series II, $\mathrm{X}=\mathrm{F}, \mathrm{R}_{1}=$ methyl, $\mathrm{R}_{2}=2-(N, N-$ diethylamino)ethyl; $\left.\mathrm{IC}_{50, \mathrm{KAN}}=0.13 \pm 0.03 \mu \mathrm{M}\right)$ and its $\mathrm{C} 8$-methylated counterpart $\mathbf{4 8 b}$ $\left(\mathrm{IC}_{50, \mathrm{KAN}}=0.17 \pm 0.04 \mu \mathrm{M}\right)$ from series III, the $\mathrm{IC}_{50, \mathrm{KAN}}$ values were virtually the same. Overall, we observed that compounds with a methyl substituent at their C8-position displayed the same or more potent activity when compared to those with a fluoro substituent, which in turn were more potent than the C8-unsubstituted compounds.

Having analyzed the effect of three substituents at the C8-position of the 1,2,4triazino[5,6b]indole-3-thioether scaffold, we next explored the effect of modifying the N5position with 11 different chemical moieties (indicated by the letters $\mathbf{a}-\mathbf{k}$ following the compound numbers in Figure 2). We varied the diversity at N5 by not substituting the amine (a) or by introducing various linear alkyl chains (b-e and $\mathbf{g}$ ), branched alkyl chains (f and $\mathbf{h}$ ), alkylaryl groups (i and $\mathbf{j}$ ), and an amido group (k). To establish the favorable N5substituents, as we did during our analysis of the C8-substituent, we compared pairs of compounds that only differed in their N5-substitutent. We first looked at the N5unsubstituted compound 11a (Table $\mathrm{S} 1$, series $\mathrm{I}, \mathrm{X}=\mathrm{H}, \mathrm{R}_{1}=\mathrm{H}$, and $\mathrm{R}_{2}=2$-(piperidin-1yl)ethyl), which was found to not be an inhibitor in our HTS. We next investigated the effect of adding linear alkyl chains at the N5-position. For compounds 11b-d, systematically increasing the size of the $\mathrm{R}_{1}$ substituent from methyl (b) to ethyl (c) and n-propyl (d) led to two-fold incremental decrease in Eis inhibitory activity (IC $5_{0, \mathrm{NEO}}=0.64 \pm 0.15 \mu \mathrm{M}, 1.1$ $\pm 0.2 \mu \mathrm{M}$, and $2.4 \pm 0.5 \mu \mathrm{M}$, respectively). This relationship between the size of $\mathrm{R}_{1}$ and Eis inhibitory activity did not perfectly translate to compounds 37b-d $\left(\mathrm{X}=\mathrm{F}, \mathrm{R}_{2}=2-(\mathrm{N}, \mathrm{N}-\right.$ diethylamino)ethyl), 39b,c (X = F, $\mathrm{R}_{2}=2$-(piperidin-1-yl)ethyl), or 48b-d $\left(\mathrm{X}=\mathrm{Me}, \mathrm{R}_{2}=2\right.$ ( $N, N$-diethylamino)-ethyl). However, we noticed by looking at IC50,KAN values that, generally, a methyl group $\left(\mathrm{R}_{1}=\mathbf{b}\right)$ at the N5-position of most compounds resulted in the best inhibitors as demonstrated with compounds $11 \mathrm{~b}, \mathbf{3 7 b}, \mathbf{3 9 b}, \mathbf{4 3 b}$, and $\mathbf{4 8 b}$. When examining the effect of branched alkyl chains ( $\mathbf{f}$ and $\mathbf{h}$ ) at the N5-position, we observed that these moieties typically decreased or abolished inhibition of Eis. For the alkylaryl (i and $\mathbf{j}$ ) and amido (k) functionalities, a concrete conclusion could not be drawn from our data due to a small sample size and the limited diversity of the alkylaryl and amido functionalities studied. It is important to note that we did not further explore the alkylaryl and amido functionalities as $R_{1}$ substituents because the resulting compounds were not as good as those with the alkyl substituents at that N5-position. Overall, we found that the methyl substituent $\left(\mathrm{R}_{1}=\mathbf{b}\right)$ was the most favored out of all N5-modifications tested. 
Next, we studied the effect of modifications at the C3-position of the 1,2,4triazino[5,6b]indole-3-thioether scaffold. The substituents at the $\mathrm{C} 3$-position were more diverse than those at the $\mathrm{C} 8$-and N5-positions, as they contained various heteroatoms. Examination of compounds 1-6, 41d, and 42b led us to conclude that any $\mathrm{C} 3$-side chain containing only carbon and hydrogen atoms (e.g., aromatic, unsaturated, or aliphatic chains) resulted in compounds with no Eis inhibitory activity. Likewise, substituents at the C3position containing oxygen atoms (e.g., carbonyl (compounds 13 and 17-30), hydroxy (compound 32b), ether (compounds 8a and 33b), morpholine (compounds 12d, 12e, 12j, 15a, 40b, 40c, 40d, and 51d)), or a cyano group (compounds 31a and 47b) were not tolerated. However, we observed that, with the exception of the morpholino and cyano groups, $\mathrm{C} 3$-side chains containing a tertiary nonaromatic nitrogen atom located 3-4 bonds away from the sulfur atom yielded potent Eis inhibitors (Figure 2). We then closely examined the steric effects of these tertiary amines on Eis inhibition. Through comparisons of pairs of compounds that differ by a 2-versus 3-carbon linker, such as compounds 11a and 14a, 36b and 43b, as well as 39b and $\mathbf{4 5 b}$, we found that, with the exception of 11a, the length of the linker did not greatly influence the $\mathrm{IC}_{50}$ values against purified Eis. To further evaluate the steric effects on Eis inhibition, compounds $36 \mathrm{~b}\left(\mathrm{R}_{2}=2-(\mathrm{N}, \mathrm{N}-\right.$

dimethylamino)ethyl; $\left.\mathrm{IC}_{50, \mathrm{KAN}}=0.43 \pm 0.04 \mu \mathrm{M}\right), 37 \mathrm{~b}\left(\mathrm{R}_{2}=2\right.$ - $(N, N$-diethylamino $)$ ethyl; $\left.\mathrm{IC}_{50, \mathrm{KAN}}=0.17 \pm 0.04 \mu \mathrm{M}\right), \mathbf{3 8 b}\left(\mathrm{R}_{2}=2\right.$-(pyrrol-1-yl)ethyl; $\left.\mathrm{IC}_{50, \mathrm{KAN}}=0.07 \pm 0.01 \mu \mathrm{M}\right)$, and 39b $\left(\mathrm{R}_{2}=2\right.$-(piperidin-1-yl)ethyl; $\left.\mathrm{IC}_{50, \mathrm{KAN}}=0.030 \pm 0.005 \mu \mathrm{M}\right)$ were assessed. In these instances, we recognized that increasing the number of carbons attached to the nitrogen atom from the dimethyl- to the diethylamino functionality correlated with increased Eis inhibitory activity as evidenced by comparison of $\mathbf{3 6} \mathbf{b}$ and $\mathbf{3 7} \mathbf{b}$. Further cyclization of the diethylamino to the pyrrolidinyl moiety led to more potent Eis inhibitors as seen when comparing 37b and 38b. Expectedly, this observation was also consistent when comparing the diethylamino-containing analogue $\mathbf{4 8 d}\left(\mathrm{IC}_{50, \mathrm{KAN}}=0.15 \pm 0.02 \mu \mathrm{M}\right)$ with the piperidinyl-containing inhibitor $\mathbf{5 0 d}\left(\mathrm{IC}_{50, \mathrm{KAN}}=0.08 \pm 0.02 \mu \mathrm{M}\right)$. Size expansion of the pyrrolidinyl ring in 38b $\left(\mathrm{IC}_{50, \mathrm{KAN}}=0.07 \pm 0.01 \mu \mathrm{M}\right)$ to the piperidinyl ring in 39b $\left(\mathrm{IC}_{50, \mathrm{KAN}}=0.030 \pm 0.005 \mu \mathrm{M}\right)$ additionally suggested that the larger six-membered heterocycle occupied the chemical space more effciently, which resulted in an improved inhibitor (2-fold improvement). Comparison of compounds $\mathbf{4 3 b}$ ( $\mathrm{IC}_{50, \mathrm{KAN}}=0.10 \pm 0.02$ $\mu \mathrm{M})$ and $44 \mathrm{~b}\left(\mathrm{IC}_{50, \mathrm{KAN}}=3.3 \pm 0.7 \mu \mathrm{M}\right)$ showed that the chemical space around the tertiary amino group has a limit, and the addition of the phenyl group was not well-tolerated. The rigidity of the tertiary amine was explored by assessing compounds $\mathbf{3 4} \mathbf{b}\left(\mathrm{IC}_{50, \mathrm{KAN}}=0.056\right.$ $\pm 0.006 \mu \mathrm{M}), \mathbf{4 3 b}\left(\mathrm{IC}_{50, \mathrm{KAN}}=0.10 \pm 0.02 \mu \mathrm{M}\right)$, and $45 \mathrm{~b}\left(\mathrm{IC}_{50, \mathrm{KAN}}=0.17 \pm 0.03 \mu \mathrm{M}\right)$. We observed that additional rigidity in the side chain as in $\mathbf{3 4 b}$ led to improved Eis inhibitory activity compared to $\mathbf{4 3 b}$ and $\mathbf{4 5 b}$. Further substitution of the piperidinyl group of $\mathbf{4 5 b}$ $\left(\mathrm{IC}_{50, \mathrm{KAN}}=0.17 \pm 0.03 \mu \mathrm{M}\right)$, as in $\mathbf{4 6}\left(\mathrm{IC}_{50, \mathrm{KAN}}=0.14 \pm 0.04 \mu \mathrm{M}\right)$, was well tolerated. Overall, our study of the $\mathrm{R}_{2}$ side chains demonstrated that side chains containing tertiary amino groups were favorable for Eis inhibition. We suspected that this phenomenon was the result of these tertiary amino groups possessing positive charges, which mimicked the positively charged nature of the AG substrates. Additionally, we found that tertiary amines with higher degree of bulkiness and rigidity were typically more potent Eis inhibitors. 
Finally, we explored the importance of the thioether at $\mathrm{C} 3$ (series II) by replacing it with an amine (series IV). When comparing series IV compounds $\mathbf{5 2}\left(\mathrm{IC}_{50, \mathrm{KAN}}=0.23 \pm 0.03 \mu \mathrm{M}\right)$ and $\mathbf{5 3}\left(\mathrm{IC}_{50, \mathrm{KAN}}=0.71 \pm 0.08 \mu \mathrm{M}\right)$ to their counterparts from series II 37b $\left(\mathrm{IC}_{50, \mathrm{KAN}}=\right.$ $0.17 \pm 0.04 \mu \mathrm{M})$ and $43 \mathrm{~b}\left(\mathrm{IC}_{50, \mathrm{KAN}}=0.10 \pm 0.02 \mu \mathrm{M}\right)$, respectively, we found that the thioether afforded compounds with better (1.4-7.1-fold) Eis inhibitory activity.

\section{Inhibition Kinetics.}

Once we completed the analysis of the $\mathrm{IC}_{50}$ measurements, we aimed to understand the mechanism by which these Eis inhibitors function. For this analysis, we selected seven inhibitors, all with an $\mathrm{IC}_{50}<1 \mu \mathrm{M}$ when using NEO as the substrate. Data analysis of kinetics as a function of the concentrations of the inhibitors and the substrate indicated that the inhibitors are competitive with NEO and yielded the inhibition constants ( $K_{\mathrm{i}}$, Table 2$)$ for compounds 36b, 37b, 37d, 37g, 39b, 39c, 39i, and 50d. Representative plots for 39i and 50d as insets in the $\mathrm{IC}_{50}$ curves are presented in Figure S81. All compounds, with the exception of 39i, showed a $K_{\mathrm{i}}<1 \mu \mathrm{M}$. From these data, the best inhibitor is $\mathbf{3 7 b}$, followed by $39 \mathrm{~b}, 39 \mathrm{c}, 37 \mathrm{~g}, \mathbf{3 6} \mathrm{b}, \mathbf{3 7 d}=\mathbf{5 0 d}$, and 39i. Interestingly, on the basis of the $\mathrm{IC}_{50}$ values, $39 \mathrm{i}$ is the best followed by $\mathbf{5 0 d}, \mathbf{3 9 b}, \mathbf{3 7} \mathbf{b}=\mathbf{3 6 b}, \mathbf{3 9 c}, \mathbf{3 7 g}$, and $\mathbf{3 7 d}$. These observations indicate that the most effective Eis inhibitors (lowest $\mathrm{IC}_{50}$ values) may not bind the tightest to the enzyme (lowest $K_{\mathrm{i}}$ values).

\section{Selectivity of Inhibitors toward Eis over Other AACs.}

Mtb contains another AAC chromosomally encoded in its genome, $\mathrm{AAC}\left(2^{\prime}\right)-\mathrm{Ic} .{ }^{21} \mathrm{To}$ determine the selectivity of the 1,2,4-triazino[5,6b]indole-3-thioether-based Eis inhibitors toward Eis, we also tested the potential ability of these compounds to inhibit other AACs. Previously, only one Eis inhibitor, from an unrelated scaffold, displayed inhibitory activity against AAC $\left(2^{\prime}\right)$-Ic. ${ }^{16}$ Compounds $\mathbf{3 6} \mathbf{b}$ and $\mathbf{3 7} \mathbf{b}$ were tested for inhibitory activity with $\operatorname{AAC}\left(2^{\prime}\right)$-Ic, AAC(3)-IV from E. coli, ${ }^{22,23}$ and AAC $\left(6^{\prime}\right)$-Ie from S. aureus. ${ }^{24}$ No inhibition of these three AACs was observed with these two compounds at concentrations up to 200 $\mu \mathrm{M}$, indicating that the compounds presented here are highly selective to Eis.

\section{Effect of Inhibitors on KAN MIC for M. tuberculosis.}

To determine if the identified Eis inhibitors could restore the activity of KAN in KANresistant $M t b$, the MIC of KAN ( MIC $_{\mathrm{KAN}}$ ) was determined in KAN-sensitive $M t b \mathrm{H} 37 \mathrm{Rv}$ and KAN-resistant Mtb strain K204 for all compounds displaying Eis inhibition $(<28 \mu \mathrm{M})$. $M t b \mathrm{~K} 204$ is genetically identical to H37Rv with the exception of one clinically important eis promoter mutation upregulating Eis expression resulting in resistance to KAN $;^{8}$ therefore, $M t b$ K204 is an excellent tool for validation of Eis inhibition as a mode of action of these compounds. Inhibitors were tested at concentrations of 100-fold of their respective $\mathrm{IC}_{50, \mathrm{KAN}}$ or at $100 \mu \mathrm{M}$ when $100 \times \mathrm{IC}_{50}$ was unknown or unachievably high. As expected, the Eis inhibitors did not affect the $\mathrm{MIC}_{\mathrm{KAN}}$ in the KAN-sensitive $M t b \mathrm{H} 37 \mathrm{Rv}$ strain. Four compounds (36b, 37b, 39b, and 43d) lowered the $\mathrm{MIC}_{\mathrm{KAN}}$ value for $\mathrm{K} 204$ from $>10 \mu \mathrm{g} / \mathrm{mL}$ in the absence of inhibitors to $2.5-5 \mu \mathrm{g} / \mathrm{mL}$. Interestingly, compound $\mathbf{4 3 d}$, while not the most potent Eis inhibitor when tested against purified Eis, reduced the $\mathrm{MIC}_{\mathrm{KAN}}$ for $M t b$ K204 to 2.5- $5 \mu \mathrm{g} / \mathrm{mL}$. Conversely, two of the most potent inhibitors, 38b and 39i, did not 
effciently restore the activity of KAN in Mtb K204. Thus, while many Eis compounds aid in the restoration of KAN activity, there is not always a direct correlation between Eis inhibition and $\mathrm{MIC}_{\mathrm{KAN}}$. There may be off-target proteins that bind the compounds and possibly a portion gets caught up in the complex cell wall of $M t b$, accounting for the large excess required to restore $\mathrm{MIC}_{\mathrm{KAN}}$.

Several factors validate Eis inhibition as the likely mechanism of action of these molecules. Compounds increased the sensitivity of Mtb K204, but not H37Rv to KAN while not affecting $M t b$ viability in general. Furthermore, we performed $\mathrm{MIC}_{\mathrm{KAN}}$ dose-dependence experiments with compounds $\mathbf{3 6} \mathbf{b}$ and $\mathbf{3 9 b}$ using a double-dilution protocol and a concentration range of Eis inhibitors of 0-32 $\mu \mathrm{M}$ (Table 3). We observed an inversely proportional relationship between the $\mathrm{MIC}_{\mathrm{KAN}}$ for $M t b \mathrm{~K} 204$ and the concentration of compound implying increasing Eis inhibition as the concentration of compound increased.

\section{Crystal Structure of Eis-CoA-Inhibitor 39b Complex Confirms Mechanism of Inhibition.}

To establish the structural basis for Eis inhibition by compounds with a 1,2,4triazino[5,6b]indole-3-thioether core, we determined the crystal structure of the enzyme in complex with $\mathrm{CoA}$ and one of the potent inhibitors, 39b (Figure 3). Compound $\mathbf{3 9 b}$ (Figure $3 \mathrm{~A}, \mathrm{~B}$ ) binds at a site that partially overlaps the site occupied by the AG tobramycin (TOB) as well as other Eis inhibitors in the literature (Figure 3C). ${ }^{12,17,18,20}$ This binding site supports the mode of action of inhibitor $\mathbf{3 9 b}$ as an AG competitive inhibitor. The crystal structure shows that the aromatic 1,2,4-triazino-[5,6b]indole core of compound $\mathbf{3 9 b}$ is stabilized by interactions with two neighboring aromatic residues, Trp36 and Phe84 (highlighted in orange) via sandwich $\pi-\pi$ stacking interactions (Figure 3B). We have previously observed similar $\pi-\pi$ interactions with Trp36 and Phe 84 during studies with Eis inhibitors of other structural classes (inhibitors a, b, and c; Figure 3D-F). Additionally, the fluorine atom at the C8-position of the 1,2,4-triazino[5,6b]indole-3-thioether core projects toward a hydrophobic pocket and interacts with the $\mathrm{C} \gamma$ of $\operatorname{Arg} 37$ ( $3.3 \AA$ away from the fluorine atom) and the $\mathrm{C} \delta$ atoms of Leu63 ( $\sim 3.6 \AA$ away from the fluorine atom) by hydrophobic interactions (Figure 3B). Hydrophobic interactions with Arg37 and Leu63 were also seen with other Eis inhibitors (Figure 3B,D-F).

While sharing some interactions with other Eis inhibitor classes, this structural scaffold enabled us to explore a novel inhibitor-Eis interface. The unique tricyclic core of $\mathbf{3 9 b}$ allows the flexible C3-linker to extend toward a large opening in the AG-binding pocket such that the piperidinyl group on the end of the linker comes into a hydrophobic contact with the aliphatic stem of Glu401. In this conformation, the linker and the piperidinyl group at the end are juxtaposed against the Asp26-Ser32 loop (Figure 3B,C). Interactions with Asp26Ser32 loop appear to be essential for Eis binding of this inhibitor class because analogues 1b, 32b, and 33b, which all have shorter $\mathrm{C} 3$ substituents, do not inhibit Eis. A water molecule located 2.8 $\AA$ away from the N2-nitrogen of the tricyclic core could form a hydrogen bond with either the hydroxyl of Ser32 or the backbone carbonyl oxygen of Gly29. Furthermore, the sulfur atom of $\mathbf{3 9 b}$ is in a hydrophobic contact with the Ce of Ile28, and the linker makes extensive van der Waals contacts with the backbone of residues 26-28. Two carbons away from the sulfur, the nitrogen atom of the piperidinyl moiety bearing a 
positive charge at the physiological $\mathrm{pH}$ forms a salt bridge with the negatively charged carboxylate of Asp26 (located $3.4 \AA$ away). Even though none of the previous Eis inhibitor classes exploits interactions with the Asp26-Ser32 as extensively as this class, among the previously discovered inhibitor classes, inhibitor $b$ interacts with this region by forming hydrogen bonds with the carboxyl group of Asp26 and the backbone N of Ile28 (Figure 3E).

This crystal structure and the SAR will guide future rational fine-tuning of the inhibitors with this new scaffold. First, other $\mathrm{C} 3$ substitutions bearing a positive charge could favorably interact with another negatively charged residue (e.g., Glu401 or the terminal carboxyl group). These electrostatic interactions support our previous SAR observations that positively charged tertiary amine functionalities such as those in compounds $37 \mathbf{b}$ or $\mathbf{3 6} \mathbf{b}$ are more tolerated compared to the neutral or partially negatively charged $\mathrm{C} 3$ substituents. In the $\mathrm{R}_{1}$ substitution of the tricyclic core, the carbon of the N5-methyl is in close proximity to the terminal carboxyl group of Eis (located $3.4 \AA$ away) and the hydroxyl group of Ser83 (located $3.1 \AA$ away), which explains why N5 alkylation with bulkier groups is not well tolerated. For instance, the IC50,NEO values for compounds $11 \mathbf{b}, \mathbf{1 1 c}$, and $11 \mathrm{~d}$ increase almost two-fold for every carbon atom added to the N5-alkyl chain. Additionally, there are a variety of ways to install different hydrogen bond donors at the N5 to take advantage of the polar protein C-terminus and side chain of Ser83. In summary, the crystal structure of the Eis-CoA-inhibitor 39b complex allowed us to compare and contrast the current class of inhibitors with previous inhibitors in the literature, explain some of the observed SAR trends, and gain insight into further optimization of this class of inhibitors. Even though these 1,2,4-triazino[5,6b]indole-3-thioether-based inhibitors are competitive KAN inhibitors as are the other previously published Eis inhibitors, the new inhibitors interact extensively with an underexplored surface of the substrate binding cavity of Eis. This property may help combat resistance to other Eis inhibitor classes that could arise due to point mutations in other inhibitor interacting surfaces.

\section{Mammalian Cytotoxicity of Eis Inhibitors.}

The ability of some molecules bearing the 1,2,4-triazino[5,6 $b$ ]indole-3-thioether scaffold to restore the activity of KAN in Mtb K204 is highly encouraging. However, to understand the utility of these compounds as potential therapeutic agents, the mammalian cell cytotoxicity needed to be examined. Four of the best compounds $(\mathbf{3 4 b}, \mathbf{3 7 b}, \mathbf{3 9 b}$, and $\mathbf{4 3 d})$ were tested against three mammalian cell lines (A549 (lung), HEK-293 (kidney), and J774A.1 (macrophage) ) alone and in the presence of $\operatorname{KAN}(50 \mu \mathrm{g} / \mathrm{mL}=86 \mu \mathrm{M})$. Compounds were evaluated for mammalian cytotoxicity at concentrations ranging from 0 to $100 \mu \mathrm{M}$. Cells displayed $100 \%$ survival rate from 0 to $12.5 \mu M$; therefore, we showed the cytotoxicity data only in the range from 12.5 to $100 \mu \mathrm{M}$ (Figure 4). The negative and positive controls used for these experiments were $0.5 \%$ DMSO (100\% cell survival) and 1\% v/v Triton-X 100 in $0.5 \%$ DMSO ( $<5 \%$ cell survival), respectively. Overall, we found that the compounds did not display significant toxicity until concentrations of $50 \mu \mathrm{M}$ with and without KAN (Figure 4). Because compounds 34b, 37b, and 39b sensitize KAN-resistant Mtb cells to KAN when used at concentrations between 5.6 to $17 \mu \mathrm{M}$, where they are not cytotoxic, these molecules are good candidates for further development into therapeutically useful KAN adjuvants for treatment of KAN-resistant $M t b$. 


\section{CONCLUSION}

In summary, by chemical, biochemical, biological, and structural studies, we discovered, optimized, and extensively characterized Eis inhibitors with the 1,2,4-triazino[5,6b]indole-3thioether scaffold. We discovered analogues with potent $\mathrm{IC}_{50}$ values and verified that these inhibitors were able to restore the $\mathrm{MIC}_{\mathrm{KAN}}$ in cellular assays. We also determined that these analogues inhibit Eis by competing with KAN via Lineweaver-Burk plots and determining the crystal structure of Eis in complex with inhibitor $\mathbf{3 9 b}$. The crystal structure further revealed that the scaffold enabled inhibitor interactions with a previously underexploited region of the Eis active site. The inhibitors were shown to not be cytotoxic at concentrations needed to restore MIC $_{\text {KAN }}$. These compounds act as KAN adjuvants against KAN-resistant Mtb. This study lays the groundwork for the further optimization of these compounds for clinical applications.

\section{Supplementary Material}

Refer to Web version on PubMed Central for supplementary material.

\section{ACKNOWLEDGMENTS}

This study was funded by a National Institutes of Health (NIH) Grant No. AI090048 (to S.G.-T.), a grant from the Firland Foundation (to S.G.-T.), and a grant from the Center for Chemical Genomics (CCG) at the University of Michigan (to S.G.-T.), as well as by startup funds from the College of Pharmacy at the University of Kentucky (to S.G.-T. and O.V.T). H.X.N. was in part supported by a Pharmaceutical Sciences Excellence in Graduate Achievement Fellowship from the College of Pharmacy at the University of Kentucky. We thank S. Vander Roest, M. Larsen, and P. Kirchhoff from the CCG at the University of Michigan for their help with HTS. We thank the staff of sector 22 (SER-CAT) of the Advanced Photon Source at the Argonne National Laboratories for their assistance with the remote X-ray diffraction data collection. The beamline use was supported, in part, by the Center for Structural Biology at the University of Kentucky. We thank Dr. Wenjing Chen for preliminary work on IC50 value determination. We thank Helen V. Waldschmidt and Matthew D. Demars for the help in the preliminary synthesis of a few molecules. Use of trade names is for identification only and does not constitute endorsement by the U.S. Department of Health and Human Services, the U.S. Public Health Service, or the CDC. The findings and conclusions in this report are those of the authors and do not necessarily represent the views of the funding agencies.

\section{ABBREVIATIONS}

AAC

$\operatorname{AcCoA}$

AMK

Eis

HTS

KAN

MDR

MIC

Mtb aminoglycoside acetyltransferase

acetyl coenzyme A

amikacin

enhanced intracellular survival

high-throughput screening

kanamycin

multidrug-resistant

minimum inhibitory concentration

Mycobacterium tuberculosis 


$\begin{array}{ll}\text { NEO } & \text { neomycin B } \\ \text { SAR } & \text { structure-activity relationship } \\ \text { TOB } & \text { tobramycin } \\ \text { TB } & \text { tuberculosis } \\ \text { XDR } & \text { extensively drug-resistant }\end{array}$

\section{REFERENCES}

(1). Raviglione M, and Sulis G (2016) Tuberculosis 2015: Burden, challenges and strategy for control and elimination. Infect. Dis. Rep 8, 6570. [PubMed: 27403269]

(2). (2016) Global Tuberculosis Report 2016, pp 1-211, World Health Organization.

(3). Unissa AN, Subbian S, Hanna LE, and Selvakumar N (2016) Overview on mechanisms of isoniazid action and resistance in Mycobacterium tuberculosis. Infect., Genet. Evol 45, 474-492. [PubMed: 27612406]

(4). Kurz SG, Furin JJ, and Bark CM (2016) Drug-resistant tuberculosis: Challenges and progress. Infect. Dis. Clin. North Am 30, 509-522. [PubMed: 27208770]

(5). Hoagland DT, Liu J, Lee RB, and Lee RE (2016) New agents for the treatment of drug-resistant Mycobacterium tuberculosis. Adv. Drug Delivery Rev 102, 55-72.

(6). Green KD, Holbrook SYL, Ngo HX, Garneau-Tsodikova S, and Firestein SM (2017) Emerging targets in anti-tubercular drug design. Antibiotic Drug Discovery: New Targets and Molecular Entities, 141-203.

(7). Green KD, and Garneau-Tsodikova S (2013) Resistance in tuberculosis: what do we know and where can we go? Front. Microbiol 4, 208. [PubMed: 23888158]

(8). Zaunbrecher MA, Sikes RD Jr., Metchock B, Shinnick TM, and Posey JE (2009) Overexpression of the chromosomally encoded aminoglycoside acetyltransferase eis confers kanamycin resistance in Mycobacterium tuberculosis. Proc. Natl. Acad. Sci. U. S. A 106, 20004-20009. [PubMed: 19906990]

(9). Reeves AZ, Campbell PJ, Sultana R, Malik S, Murray M, Plikaytis BB, Shinnick TM, and Posey JE (2013) Aminoglycoside cross-resistance in Mycobacterium tuberculosis due to mutations in the $5^{\prime}$ untranslated region of whiB7. Antimicrob. Agents Chemother 57, 1857-1865 [PubMed: 23380727]

(10). Campbell PJ, Morlock GP, Sikes RD, Dalton TL, Metchock B, Starks AM, Hooks DP, Cowan LS, Plikaytis BB, and Posey JE (2011) Molecular detection of mutations associated with firstand second-line drug resistance compared with conventional drug susceptibility testing of Mycobacterium tuberculosis. Antimicrob. Agents Chemother 55, 2032-2041. [PubMed: 21300839]

(11). Chen W, Biswas T, Porter VR, Tsodikov OV, and Garneau-Tsodikova S (2011) Unusual regioversatility of acetyltransferase Eis, a cause of drug resistance in XDR-TB. Proc. Natl. Acad. Sci.U. S. A 108, 9804-9808. [PubMed: 21628583]

(12). Houghton JL, Biswas T, Chen W, Tsodikov OV, and Garneau-Tsodikova S (2013) Chemical and structural insights into the regioversatility of the aminoglycoside acetyltransferase Eis. ChemBioChem 14, 2127-2135. [PubMed: 24106131]

(13). Green KD, Chen W, and Garneau-Tsodikova S (2011) Effects of altering aminoglycoside structures on bacterial resistance enzyme activities. Antimicrob. Agents Chemother 55, 32073213. [PubMed: 21537023]

(14). Chen W, Green KD, and Garneau-Tsodikova S (2012) Cosubstrate tolerance of the aminoglycoside resistance enzyme Eis from Mycobacterium tuberculosis. Antimicrob. Agents Chemother 56, 5831-5838. [PubMed: 22948873] 
(15). Tsodikov OV, Green KD, and Garneau-Tsodikova S (2014) A random sequential mechanism of aminoglycoside acetylation by Mycobacterium tuberculosis Eis protein. PLoS One 9, e92370. [PubMed: 24699000]

(16). Green KD, Chen W, and Garneau-Tsodikova S (2012) Identification and characterization of inhibitors of the aminoglycoside resistance acetyltransferase Eis from Mycobacterium tuberculosis. ChemMedChem 7, 73-77. [PubMed: 21898832]

(17). Willby MJ, Green KD, Gajadeera CS, Hou C, Tsodikov OV, Posey JE, and Garneau-Tsodikova S (2016) Potent inhibitors of acetyltransferase Eis overcome kanamycin resistance in Mycobacterium tuberculosis. ACS Chem. Biol 11, 1639-1646. [PubMed: 27010218]

(18). Garzan A, Willby MJ, Green KD, Gajadeera CS, Hou C, Tsodikov OV, Posey JE, and GarneauTsodikova S (2016) Sulfonamide-based inhibitors of aminoglycoside acetyltransferase Eis abolish resistance to kanamycin in Mycobacterium tuberculosis. J. Med. Chem 59, 10619-10628. [PubMed: 27933949]

(19). Garzan A, Willby MJ, Green KD, Tsodikov OV, Posey JE, and Garneau-Tsodikova S (2016) Discovery and optimization of two Eis inhibitor families as kanamycin adjuvants against drugresistant M. tuberculosis. ACS Med. Chem. Lett 7, 1219-1221.

(20). Garzan A, Willby MJ, Ngo HX, Gajadeera CS, Green KD, Holbrook SYL, Hou C, Posey JE, Tsodikov OV, and Garneau-Tsodikova S (2017) Combating Eis-mediated kanamycin resistance of M. tuberculosis by novel pyrrolo[1,5-a]pyrazine-based Eis inhibitors. ACS Infect. Dis 3, 302309. [PubMed: 28192916]

(21). Hegde SS, Javid-Majd F, and Blanchard JS (2001) Overexpression and mechanistic analysis of chromosomally encoded aminoglycoside $2^{\prime}$-N-acetyltransferase (AAC $\left(2^{\prime}\right)$-Ic) from Mycobacterium tuberculosis. J. Biol. Chem 276, 45876-45881. [PubMed: 11590162]

(22). Magalhaes ML, and Blanchard JS (2005) The kinetic mechanism of AAC3-IV aminoglycoside acetyltransferase from Escherichia coli. Biochemistry 44, 16275-16283. [PubMed: 16331988]

(23). Green KD, Chen W, Houghton JL, Fridman M, and Garneau-Tsodikova S (2010) Exploring the substrate promiscuity of drug-modifying enzymes for the chemoenzymatic generation of $\mathrm{N}$ acylated aminoglycosides. ChemBioChem 11, 119-126. [PubMed: 19899089]

(24). Daigle DM, Hughes DW, and Wright GD (1999) Prodigious substrate specificity of AAC(6')$\operatorname{APH}\left(2^{\prime \prime}\right)$, an aminoglycoside antibiotic resistance determinant in enterococci and staphylococci. Chem. Biol 6, 99-110. [PubMed: 10021417] 
Step 2: $\mathbf{4 6}$ molecules from HTS with the following core:<smiles>[X]c1ccc2c(c1)c1nnc(S)nc1n2[R]</smiles>

Step 3: Validation of 7 of the $46 \mathrm{cpds}$ above +17 purchased analogues

Step 4: Validation 22 synthesized analogues +2 re-synthesized of the $46 \mathrm{cpds}$ above

Step 5: Determination of $1 C_{50}$ values for 46 Eis inhibitors from steps $3-4$

Step 6: Determination of MICs of

KAN with 28 Eis inhibitors with

$I_{50}$ values $<28 \mu \mathrm{M}$

4 Eis inhibitors with

$M_{\text {KAN }} \leq 2.5-5 \mu \mathrm{g} / \mathrm{mL}$

against Mtb K204

Figure 1.

Stepwise cone diagram showing the winnowing of $\sim 23000$ compounds to the four Eis inhibitors that restored KAN activity in Mtb K204. 


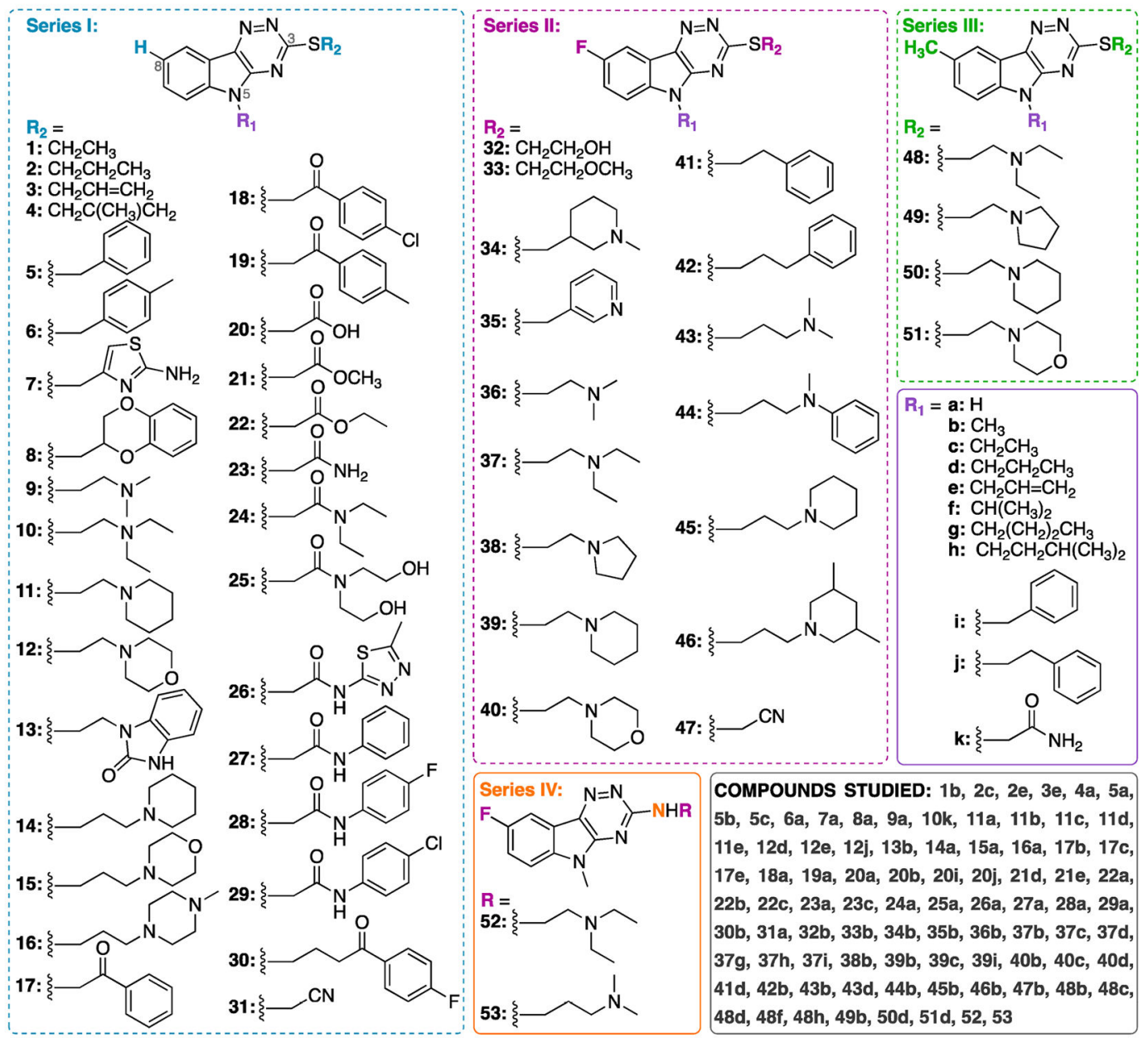

ORIGIN OF COMPOUNDS:

HTS only: 1b, 2c, 2e, 3e, 4a, 5a, 5b, 5c, 6a, 7a, 8a, 11a, 12d, 12e, 12j, 13b, 15a, 17b, 17c, 17e, 18a, 19a, 20a, 20b, 20i, 20j, 21d, 21e, 22a, 22b, 22c, 26a, 27a, 28a, 29a, 37c, 40c, 40d, 51d

HTS \& repurchased: 14a, 23a, 23c, 37d, 40b

Not in HTS, only purchased: 9a, 10k, 11b, 11c, 11d, 11e, 16a, 24a, 25a, 30b, 31a, 37g, 37i, 39c, 39i, 41d, 50d

Synthesized: 32b, 33b, 34b, 35b, 36b, 37h, 38b, 42b, 43b, 43d, 44b, 45b, 46b, 47b, 48b, 48c, 48d, 48f, 48h, 49b, 52,53

HTS, repurchased, \& re-synthesized: $37 \mathrm{~b}$

HTS, repurchased, re-synthesized, \& crystallized: 39b

Figure 2.

Structures of all molecules used in this study along with their origins. Note: At the bottom of the figure, the compound numbers listed in orange indicate that the compounds were tested in the HTS only. Those listed in pink were tested in the HTS and repurchased for validation. Those listed in gray were compounds that were not present in the HTS but were purchased to expand the preliminary SAR study. Those in green were new derivatives synthesized to further expand our SAR study. Compound 37b is in purple as it was present in the HTS, repurchased, and resynthesized to confirm the values obtained for purchased material. Compound 39b is in blue as, not only was it present in the HTS, repurchased, and resynthesized, but was additionally crystallized with Eis. All compounds (except those listed with orange numbers) had an $\mathrm{IC}_{50}$ or/and $\mathrm{MIC}_{\mathrm{KAN}}$ value determined as presented in Table 1. 
A
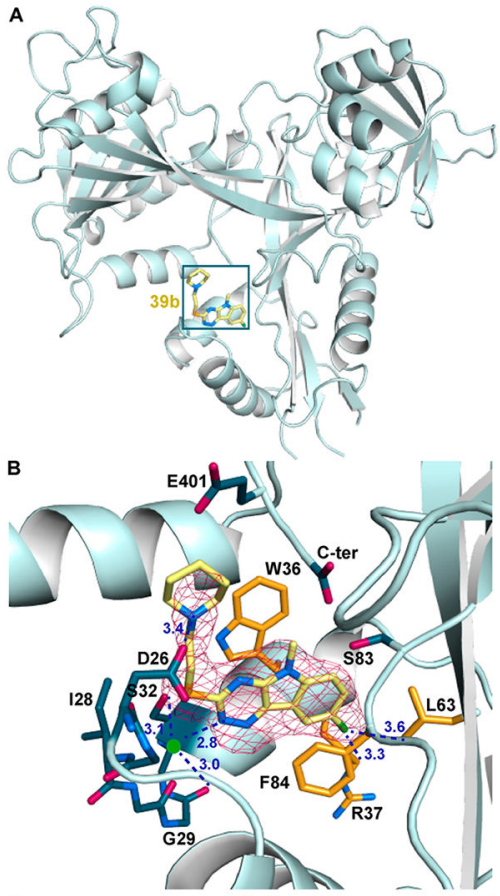

C

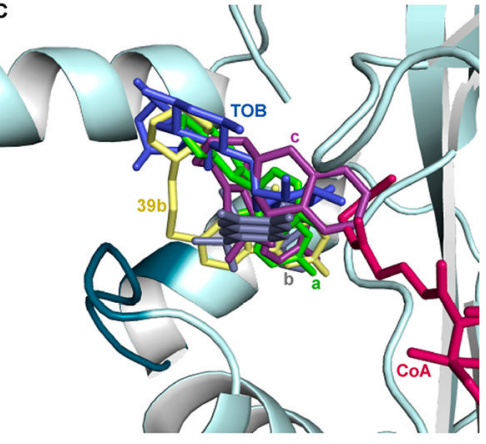

D

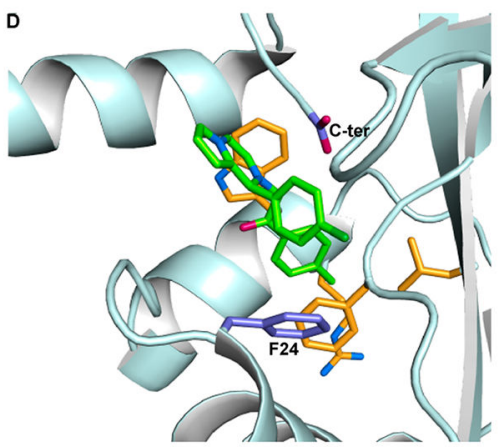

E

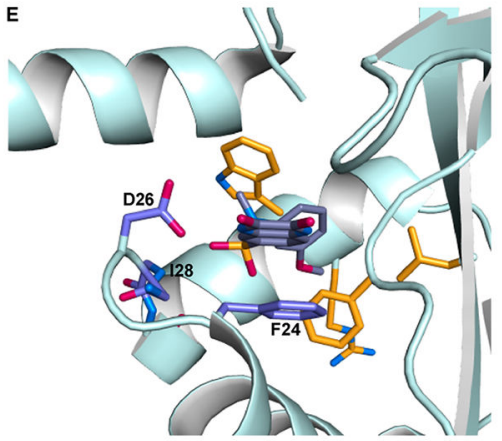

$\mathbf{F}$
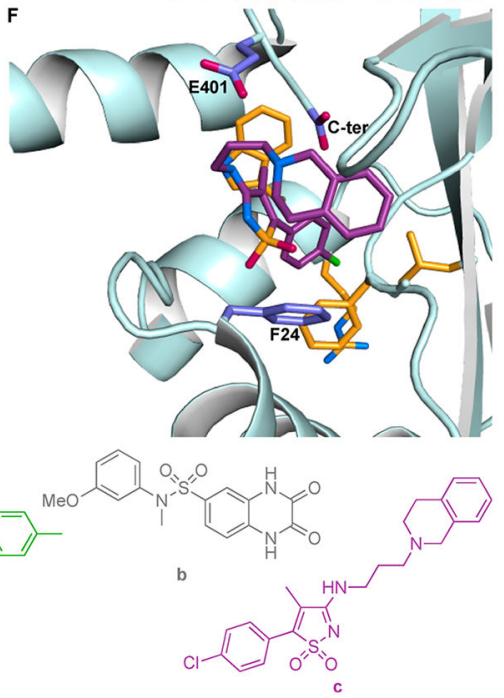

Figure 3.

(A) Crystal structure of one of the six monomers of the EisC204A-CoA-inhibitor 39b (shown as yellow sticks in a box) complex. Note: For the sake of simplicity, the CoA is omitted in this figure, but is shown in panel C. (B) Zoom-in view of the binding pocket of compound $39 \mathrm{~b}$. The strong omit $\mathrm{F}_{0}-\mathrm{F}_{\mathrm{c}}$ electron density map contoured at $3 \sigma$ generated without compound $\mathbf{3 9 b}$ is shown by a magenta mesh. The amino acid residues interacting with compound 39b are depicted in dark turquoise. The conserved residues that interact with 39b and previously published Eis inhibitors are depicted as orange sticks. The Asp26-Ser32 loop is shown as dark turquoise sticks. The $\mathrm{C}$-terminus is labeled as $\mathrm{C}$-ter. A water molecule is shown as a green sphere. The distances between atoms of the inhibitor $\mathbf{3 9 b}$ and those of amino acid residues of the Eis protein are shown by a dark blue dashed line and are in A. For 
compound 39b, the carbon, oxygen, nitrogen, fluorine, and sulfur atoms are colored pale green, red, blue, dark green, and orange, respectively. (C) Compound 39b is overlapped with tobramycin (TOB) and previously published Eis inhibitors. The previously published structure of bound TOB (PDB ID 4JD6 ${ }^{12}$ ) is in blue. Bound CoA is depicted as red sticks. (D) Inhibitor "a", a pyrrolo[1,5-a]pyrazine-based Eis inhibitor (labeled 2k* in ref 20, PDB ID 5TVJ), is depicted as green sticks. (E) Inhibitor "b", a sulfonamide-based inhibitor (labeled 39 in ref 18 PDB ID 5IV0), is depicted as gray sticks. (F) Inhibitor "c", an isothiazole S,S-dioxide heterocyclic core (labeled 11c in ref 17 PDB ID 5EBV) is depicted as purple sticks. Note: In panels D-F, amino acid residues that interact specifically with the inhibitors presented are depicted in lilac. (G) Chemical structures of TOB as well as inhibitors 39b and "a-c". 

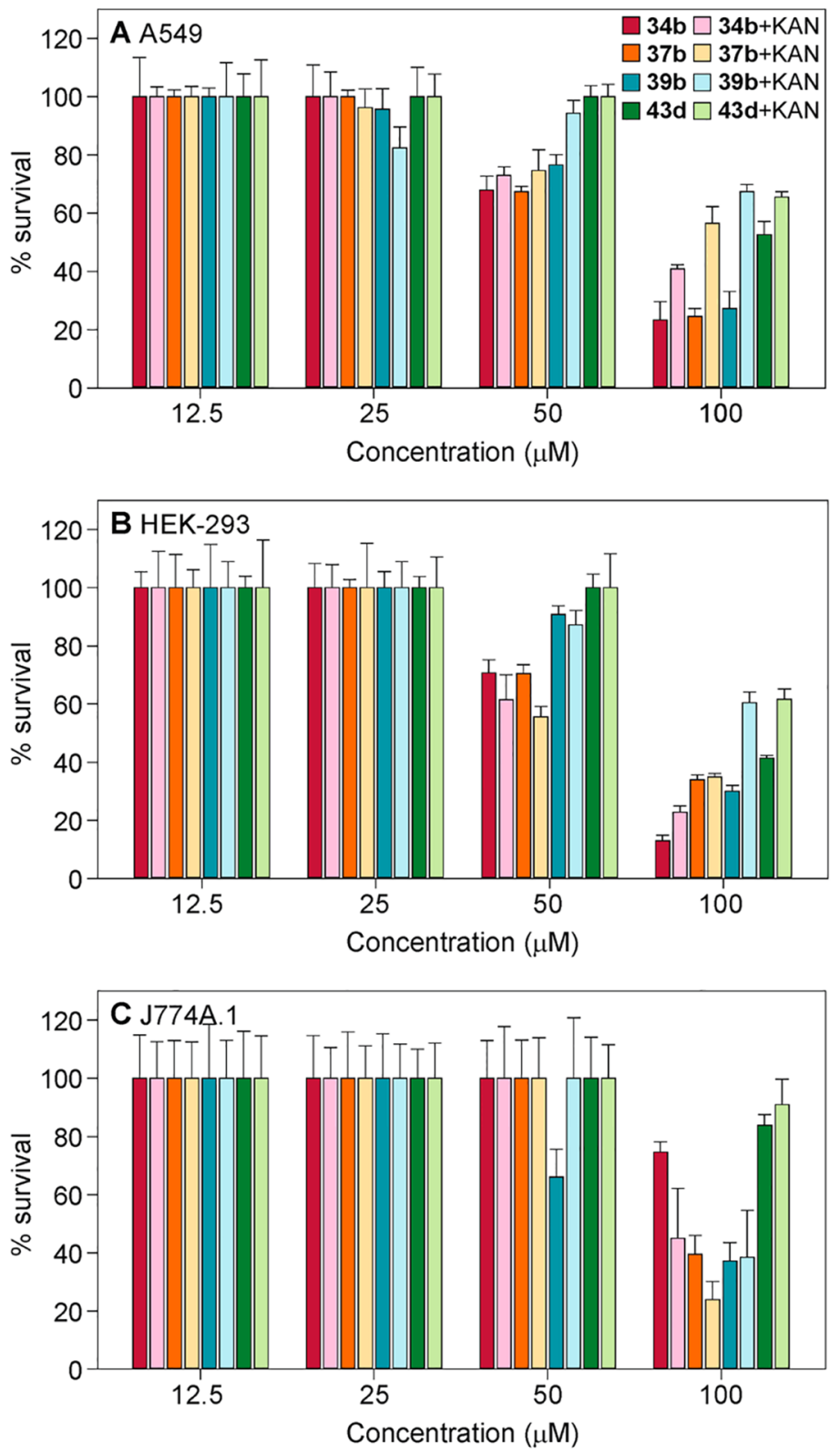

Figure 4.

Mammalian cytotoxicity of selected compounds $(\mathbf{3 4 b}, \mathbf{3 7 b}, \mathbf{3 9 b}$, and $\mathbf{4 3 d})$ alone (depicted as dark color columns) or in the presence of $50 \mu \mathrm{g} / \mathrm{mL}(86 \mu \mathrm{M}) \mathrm{KAN}$ (depicted as light color column directly to the right of the dark color column for the compound alone) against (A) A549, (B) HEK-293, and (C) J774A.1 cells. Note: No cytotoxicity was observed from 0 to $12.5 \mu \mathrm{M}$. 
<smiles>[X]c1ccc2c(c1)C(=O)C(=O)N2</smiles>

54: $\mathrm{X}=\mathrm{F}$ 55: $\mathrm{X}=\mathrm{CH}_{3}$
56: $\mathrm{X}=\mathrm{F}$

57: $\mathrm{X}=\mathrm{CH}_{3}$ 56/58b: $\mathrm{R}_{1}=\mathrm{CH}_{3}$

56/58d: $\mathrm{R}_{1}=\mathrm{CH}_{2} \mathrm{CH}_{2} \mathrm{CH}_{3}$

56/58h: $\mathrm{R}_{1}=\mathrm{CH}_{2} \mathrm{CH}_{2} \mathrm{CH}\left(\mathrm{CH}_{3}\right)_{2}$

57/59b: $\mathrm{R}_{1}=\mathrm{CH}_{3}$

57/59c: $\mathrm{R}_{1}=\mathrm{CH}_{2} \mathrm{CH}_{3}$

57/59d: $\mathrm{R}_{1}=\mathrm{CH}_{2} \mathrm{CH}_{2} \mathrm{CH}_{3}$

57/59f: $\mathrm{R}_{1}=\mathrm{CH}\left(\mathrm{CH}_{3}\right)$

57/59h: $\mathrm{R}_{1}=\mathrm{CH}_{2} \mathrm{CH}_{2} \mathrm{CH}\left(\mathrm{CH}_{3}\right)_{2}$<smiles>[X]c1ccc2c(c1)/C(=N/NC(=N)S)C(=O)N2CC</smiles>

$\mathbf{R}_{1}$

58: $\mathrm{X}=\mathrm{F}$ 59: $\mathrm{X}=\mathrm{CH}_{3}$

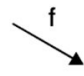<smiles>[X]c1ccc2c(c1)c1nnc(S)nc1n2C</smiles>

$R_{1}$

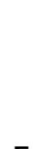<smiles>C[13CH]</smiles><smiles>Cn1c2ccc(F)cc2c2nnc(SCC#N)nc21</smiles>

47b

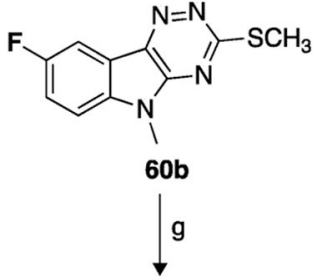<smiles>Cn1c2ccc(F)cc2c2nnc(S(C)(=O)=O)nc21</smiles><smiles>[R2]N([R3])NC(=[V])Nc1nc2c(c3ccccc13)c1cc(F)ccc1n2C</smiles>

52: $\mathrm{n}=2, \mathrm{R}_{3}=\mathrm{R}_{4}=\mathrm{CH}_{2} \mathrm{CH}_{3}$ 53: $\mathrm{n}=3, \mathrm{R}_{3}=\mathrm{R}_{4}=\mathrm{CH}_{3}$

a) $\mathrm{Cs}_{2} \mathrm{CO}_{3}$, alkyl halide, $\mathrm{MeCN}$, rt, quant.; b) 1. thiosemicarbazide, $\mathrm{K}_{2} \mathrm{CO}_{3}$ or $\mathrm{Cs}_{2} \mathrm{CO}_{3}, \mathrm{H}_{2} \mathrm{O}$, reflux, 2. $\mathrm{HCl}, 22-52 \%$; c) alkyl halide, $\mathrm{KI}$, $\mathrm{K}_{2} \mathrm{CO}_{3}$, DMF, $100{ }^{\circ} \mathrm{C}, 14-82 \%$; d) $\mathrm{NaH}, \mathrm{Mel}, \mathrm{CH}_{2} \mathrm{Cl}_{2}, 0{ }^{\circ} \mathrm{C}$-rt, $47 \%$; e) $58 \mathrm{~b}$, bromoacetonitrile, DMF, $\mathrm{K}_{2} \mathrm{CO}_{3}$, reflux, $12 \mathrm{~h}, 63 \%$; f) $58 \mathrm{~b}$, $\mathrm{Cs}_{2} \mathrm{CO}_{3}, \mathrm{Mel}, \mathrm{MeCN}, \mathrm{rt}, 2 \mathrm{~h}, 91 \%$; g) $\mathrm{m}$-CPBA, $\mathrm{CH}_{2} \mathrm{Cl}_{2}$, rt, $24 \mathrm{~h}, 45 \%$; h) $\mathrm{N}, \mathrm{N}$-dialkylaminoalkylamine, THF, reflux, 2-6 h, 8-42\%.

Scheme 1.

Synthetic Schemes Used for the Synthesis of 24 Compounds Generated in This Study 


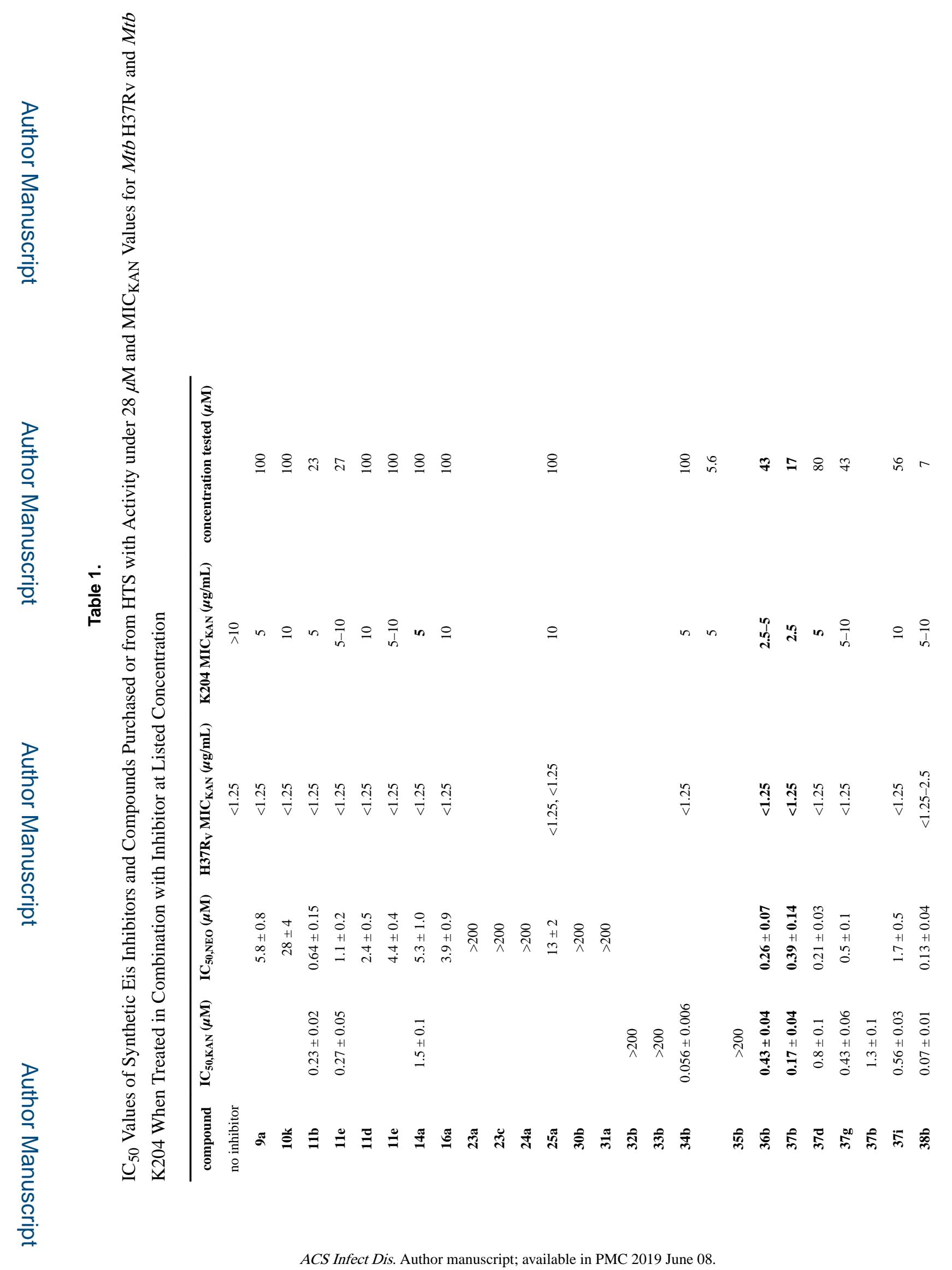


Ngo et al.

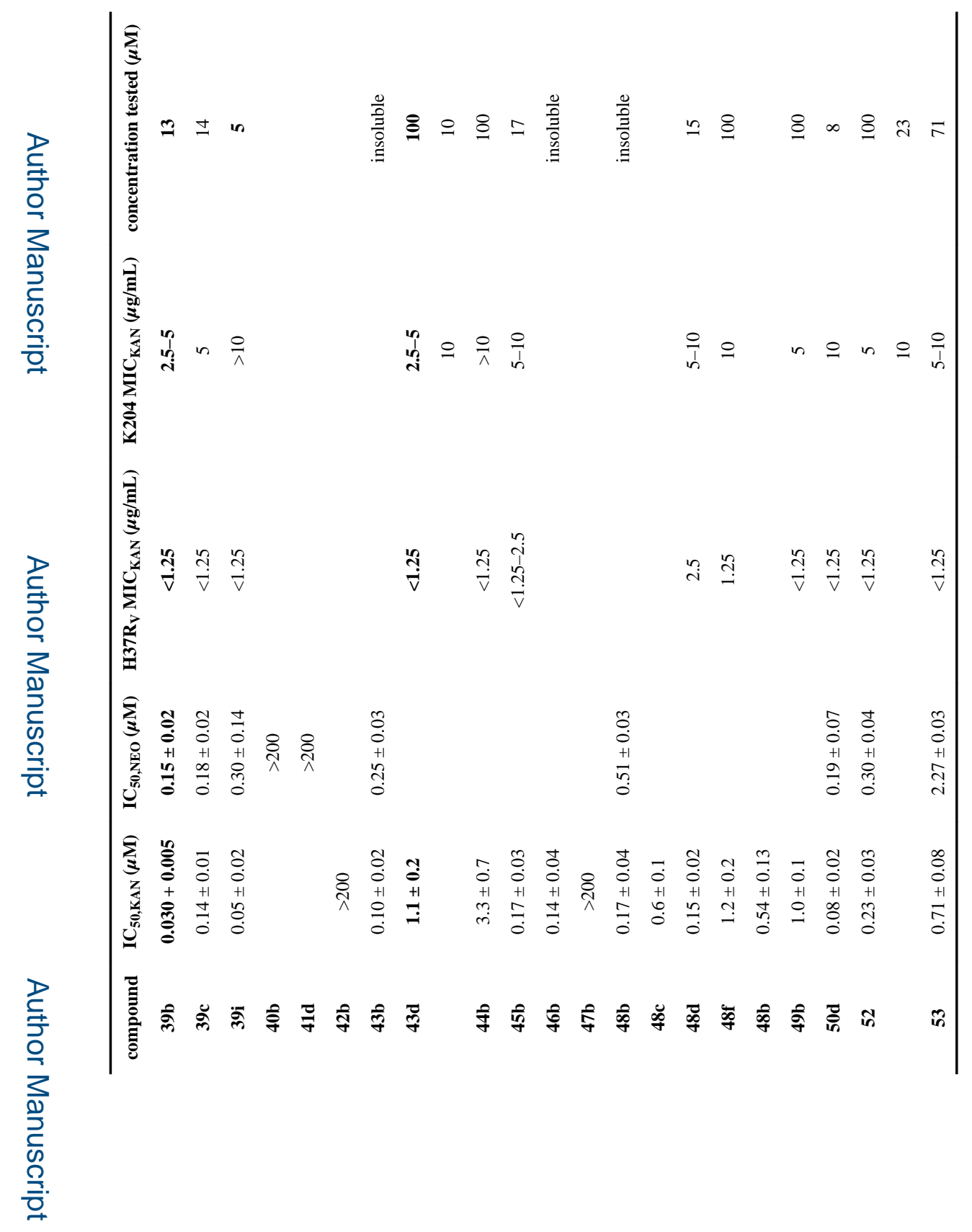

로을

ACS Infect Dis. Author manuscript; available in PMC 2019 June 08. 
Table 2.

$K_{\mathrm{i}}$ Values Determined Using Regression Analysis for Eis Inhibitors Displaying $\mathrm{IC}_{50}$ Value $<1 \mu \mathrm{M}$ Using NEO as Substrate

\begin{tabular}{cc}
\hline compound & $\boldsymbol{K}_{\mathrm{i}}(\boldsymbol{\mu} \mathbf{M})$ \\
$\mathbf{3 6 b}$ & $0.6 \pm 0.2$ \\
$\mathbf{3 7 b}$ & $0.08 \pm 0.01$ \\
$\mathbf{3 7 d}$ & $0.82 \pm 0.48$ \\
$\mathbf{3 7 g}$ & $0.45 \pm 0.05$ \\
$\mathbf{3 9 b}$ & $0.16 \pm 0.03$ \\
$\mathbf{3 9 c}$ & $0.32 \pm 0.13$ \\
$\mathbf{3 9 i}$ & $1.4 \pm 0.3$ \\
$\mathbf{5 0 d}$ & $0.89 \pm 0.23$ \\
\hline
\end{tabular}


Table 3.

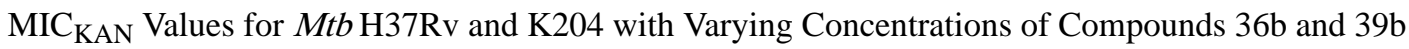

\begin{tabular}{|c|c|c|c|c|}
\hline \multirow[b]{2}{*}{ concentration tested $(\mu \mathrm{M})$} & \multicolumn{2}{|c|}{ 36b } & \multicolumn{2}{|c|}{$39 \mathrm{~b}$} \\
\hline & H37Rv MIC KAN $(\mu \mathrm{g} / \mathrm{mL})$ & $\mathrm{K}^{204} \mathrm{MIC}_{\mathrm{KAN}}(\mu \mathrm{g} / \mathrm{mL})$ & H37Rv MIC $_{\text {KAN }}(\mu \mathrm{g} / \mathrm{mL})$ & $\mathrm{K}^{204} \mathrm{MIC}_{\mathrm{KAN}}(\mu \mathrm{g} / \mathrm{mL})$ \\
\hline 0 & $1.25,2.5$ & 20,20 & $1.25,2.5$ & 20,20 \\
\hline 0.5 & $1.25,1.25$ & 10,20 & $1.25,1.25$ & 10,20 \\
\hline 1 & $1.25,1.25$ & 10,20 & $1.25,1.25$ & 10,20 \\
\hline 2 & $1.25,1.25$ & 10,20 & $0.625,1.25$ & 10,10 \\
\hline 4 & $0.625,1.25$ & 10,10 & $0.625,1.25$ & 5,10 \\
\hline 8 & $0.625,1.25$ & 5,5 & $0.625,1.25$ & 5,5 \\
\hline 16 & $0.625,1.25$ & 5,5 & $0.625,1.25$ & 5,5 \\
\hline 32 & $0.625,1.25$ & 5,5 & $0.625,1.25$ & $2.5,2.5$ \\
\hline
\end{tabular}

